\title{
Foreign Direct Investment's Trust in Moroccan \\ Competitiveness Poles: A Case Study of the Automotive Industry in Tangier
}

\author{
Sabrine BELQASMI \\ Research Laboratory in Strategy, Management and Governance, National School of \\ Commerce and Management (NSCM), Tangier, Morocco \\ Abdelmalek Essaâdi University, Tetouan, Morocco \\ E-mail: sabrine_belqasmi@yahoo.fr
}

Received: April 7, 2018 Accepted: April 26, 2018 Published: June 14, 2018

doi:10.5296/bms.v9i1.12969ＵRL: https://doi.org/10.5296/bms.v9i1.12969

\begin{abstract}
Given the need to diversify its activities to revitalize its economy, and with the ambition of becoming a preferred destination for foreign direct investment (FDI), Morocco has put in place a package of measures and reforms, and opted for a policy Creation of clusters and competitiveness poles based on the local specificities of its territory.

In this context, the government launched the "National Pact for Industrial Emergence" (2009-2015) [and subsequently the "Industrial Acceleration Plan" (2014-2020)] which aims at the installation of the Integrated Industrial Platforms (2IP) which are the Moroccan version of competitiveness poles, dedicated to the Moroccan trades of the world, and offered under incentive conditions to domestic and international investors (FDIs) in order to form a business ecosystem where the interaction between actors requires a relationship dynamic based on trust.

By using a qualitative method based on the case study, we study in this paper, this relational dynamic, on a sample of 15 companies from the automotive industry in Tangier, using the three components of the theoretical grid of Zucker (1986): characteristic-based Trust, relational trust, institutional trust, highlighting the issue of the contribution of trust to the emergence of the business ecosystem Tangier city as an automotive competitiveness pole,
\end{abstract}


The results obtained clearly show that two of the three components of our reading grid are simultaneously intertwined within our business ecosystem, namely institutional trust and characteristic-based trust with dominance of the first confirming the trust of FDI in Moroccan institutions, and that this trust is fostered by Cultural Specificities of the country.

Keywords: FDI, business ecosystem, trust

JEL Classification: D23, F21, F43, L14, L21, L78, M21, O21, O43 


\section{Introduction}

In a world marked by an increasing globalization, we are witnessing, throughout the world, a strong competition between territories for the attractiveness and reception of foreign direct investment (FDI), emphasizing on the phenomenon of territorial economy where "the reinforced relation of local territories to the world economy is expressed by the neologism" glocalisation", contracting the globalization and the localization". (PECQUEUR, 2007, p. 43)

In Morocco, the presence of foreign companies dates back to the mid-nineteenth century (Miège, 1989). To confirm this process and encourage territorial attractiveness and local development, Morocco has opted for a policy of creating competitiveness clusters and Technopark, based on the local specificities of its territory, and which aims to develop in sectors of activity, a level of excellence to generate a dynamic of new growth,

In this context, the government launched the "National Pact for Industrial Emergence" (2009-2015) [and subsequently the "Industrial Acceleration Plan" (2014-2020)] aimed at the installation of Integrated Industrial Platforms (2IP), as a Moroccan business ecosystem model, dedicated to the Moroccan trades of the world advocated by McKinsey, and offered under incentive conditions for domestic and international investors (FDI) with the aim to build a strong industrial sector and create a virtuous circle of regional growth, and to form business ecosystems that can play a fundamental role not only in the sharing of value by all members of the ecosystem, but also in management of the contributions of the various actors and enabling interdependent actors to share their ideas and technologies on the basis of links established between them on the basis of a relational dynamic based on trust which constitutes a ferment of these links.

Among the sectors to which this program was dedicated, it is the automotive sector that has marked the city of Tangier promising the city to become an important hub of the European automobile system and the new ecosystem of the Moroccan automotive industry and whose relational dynamics deserves to be studied.

It is in this perspective, and to emphasize the trust as a lubricant of relations of the Moroccan ecosystem, that we try in this contribution to associate in the same study the concepts "FDI", "ecosystem" and "trust", which is certainly unusual, and it puts forward questions such as:

- How is trust built between actors (including FDI) within a business ecosystem?

- What are the singularities of the relational dynamics of the Moroccan business ecosystem that favor its attractiveness to FDI? Through these questions we try to analyze in a new light the attractiveness to FDI and the emergence of Tangier as a pole of the automotive industry.

The main objective therefore set for our research is to enrich the field of analysis of the Moroccan ecosystem by making a contribution on the relationship dynamics of trust within the Tangier cluster. Analyzing, therefore, the Moroccan ecosystem, means trying to better understand this key role of trusted third party played by the State which makes the Tangier 
platform an attractive ecosystem for FDI in the automotive sector.

Our present paper is structured as follows: in a first part dedicated to a non-exhaustive literature review and theoretical framework, we develop theoretical explanations and anchoring of the determinants of FDI, business ecosystem, and trust, which we end with our grid of trust reading which is none other than Zucker's grid. The second part will be devoted to the presentation of the adopted methodology in which we provide in detail the explanations of our epistemological and methodological choices. Finally, we expose and discuss the results obtained in a third part.

\section{Literature Review and Theoretical Framework}

The end of the twentieth and the beginning of the twenty-first century are marked by a process of accelerating the globalization of trade (development of information and communication technologies, increased mobility of capital and goods, etc.), which gives more freedom for companies to locate their locations.

However, this increased freedom in the choice of locations contributes to exacerbating competition between territories around the world to attract as much FDI as possible.

The analysis, therefore, of the decision of internationalization of the companies, is to bring elements of answer to the following question: "What are the reasons which push the companies to become multinational and to invest abroad to produce the same only in the country of origin?"

\subsection{Theoretical Explanation of FDI Determinants}

In its attempts to explain, the literature, which deals with the flows, causes and effects of FDI, brings together in its theoretical frameworks analysis, specific aspects of firms and others related to host countries, and suggests that the theories concerned can be divided into several schools including the modernization school under its two approaches: on the one hand the perfect market approach, and on the other hand the imperfect market approach that brings together the theory of the organization. industrial theory, the theory of the firm, the theory of internationalization, localization and globalization, and the school of integration which takes into account the variables macro- (the whole economy), micro- (the firm) and mesoeconomic (the institutions), and which gathers on the one hand, "the eclectic approach" or "the OLI paradigm", and on the other hand, the paradigm "ESP": "Environment, System, Politic" And the theory of institutional adaptation that characterizes host-country institutions as a determinant of FDI flows;

Indeed, since the 1960s, the theory of the MNFs (Multinational Firms) and especially the theory of industrial organization with Hymer (1996) as one of its precursors has tried to emphasize the notion of imperfect competition which affects firms' performance and pushes them to enter markets before their competitors, Vernon (1966) explains FDI through the theory of international trade and the product life cycle. According to this author when the product becomes mature, labor costs become very important in the production process, it is at 
this time that firms relocate in search of low production costs.

From the 1970s, new attempts to explain these FDIs were made, first, with the firm's theory and the works of Buckley and Casson (2001) and Hirsch (1976) who tried to explain the problem. development of FDI through the theory of transaction costs by conducting a trade-off between the firm's three modes of foreign market exploration: foreign direct investment (FDI), export, or license sale, but then and especially with Dunning's eclectic approach or the OLI Paradigm, which appears to be the most relevant and widely used and whose principle is based on the fact that the firm's ownership of tangible or intangible benefits or assets " Ownership "gives her the privilege of choosing an attractive" Location "to invest in and "Internalize" transaction costs.

Starting in the 1980s, the synthetic analysis of Mucchielli (1985) provided a new combination of advantages, namely the country's comparative advantage over its partners as a result of its supply of factor and technological endowments, and the competitive advantage of the firm generated by its internal characteristics

From the 90s and during the 2000s, Mucchielli (1991), deepening the synthetic analysis, indicates that the interconnection between the environment (natural resources, human and infrastructure), the system (political, economic and social institutions) and politics (actions led by governments), make it possible to understand FDI flows: "It is then the simultaneity of the three competitive, comparative and strategic advantages for a firm, which engenders a behavior of international cooperation agreement instead of a direct investment, export or license sale " (pp. 133-134). Wilhelms (1998), for his part, uses for his analysis, an innovative concept called "Institutional fitness" which finds its basis in the integrationist theory of FDI and which states that FDI is essentially determined by the institutional variables likely to bring changes in policy, laws and their applications. In the same sense, Globerman and Shapiro (1999) show that good institutions can have the same effects on outgoing and incoming FDI insofar as they create, abroad, a favorable environment for multinationals.

In the same perspective, the works carried out by $\mathbf{K}$. Sekkat and $\mathbf{M}$. Veganzones-Varoudakis (2004) show that the reforms which relate to the investment climate (political and economic) are the determining factors of the attractiveness of FDI.

Ultimately, the choice of location of FDI relates, essentially, to the "OLI paradigm" and the own characteristics of host countries that try to make their territories more attractive and turn them into more competitive business ecosystems where:

"A company is viewed not as a member of a single industry but as part of a business ecosystem that crosses a variety of industries. In a business ecosystem, companies co-evolve capabilities around a new innovation: they work cooperatively and competitively to support new products, satisfy customer needs, and eventually incorporate the next round of innovations" as suggested by (Moore 1993, p. 76), and where trust is a key factor in exchange and management of inter-organizational exchanges and especially in the influx of 
FDI to these ecosystems.

\subsection{The Business Ecosystem: A Shared Strategic Destiny of Enterprises}

The development of territories around notions of knowledge, skills and ability of the various actors involved (public bodies, companies, training centers) to engage in genuine collaboration is a crucial issue in the development and viability of an ecosystem.

Moore (1993) describes an ecosystem as "an economic community supported by a foundation of interacting organizations and individuals" and states that "members of a business ecosystem work co-operatively and competitively to support new products, satisfy customer needs, and eventually incorporate the next round of innovations " (p.76).

In the same perspective, Torres-Blay (2000) defines, for his part, an ecosystem as being: "an heterogeneous coalition of companies from different sectors forming a strategic community of interests or values structured in a network around a leader who manages to impose or share his business idea or technological standard " (p.246)

Whether defined as "economic community" or as "heterogeneous coalition of companies", the accent is put in an ecosystem, on the partnership character that dominates the relations between the companies of this ecosystem and that draws its very basis, according to Gueguen and Torres (2004), of three streams of thought: from the theory of complex systems based on the evolution of business strategies according to their relation considered dynamic: Lengnick-Hall and Wolff (1999) believe that "strategic success depends on a company's ability to thrive in non-linear dynamic systems that rely on network feedback and emerging relationships. Effective strategies therefore require a mixture of competition and cooperation." ( $p$ 1114), from the theory of collective strategies based on the principle of adaptation to the environment through collaboration that requires the company to develop a common strategy instead of acting individually, such as affirmed by Astley and Fombrun (1983) "[..] This analysis highlights the importance of collective and non-individual forms of organizational adaptations, and suggests the usefulness of the concept of" collective strategy ": the joint mobilization of resources and the formulation of actions within organizations' communities." (p.578), or the theory of standards which stipulates the development of one or more central competences shared by several companies to arrive at a standard or a technological standard often imposed by the most influential actors of the ecosystem: " despite their simplicity, standards are a critical part of what makes business ecosystems work: they are an essential tool for structuring the ecosystem, and an instrument used by the most influential actors to exercise their power over others " (Iansiti and Levien, 2004, p. 162)

\subsection{Theoretical Anchor of Trust}

The concept of trust has historically emerged in the field of psychology (Deutsh, 1958) and has touched on several domains: social psychology (Lewicki and Bunker, 1996), philosophy (Williams, 1988), sociology (Fukuyama, 1995), management (Ireland and al. 2003), strategic management (Barney and Hansen, 1994), Ring and Van de Ven (1994), Hosmer (1995) and 
Ring (1996), economics (Dasgupta, 1988), Marketing (Castaldo, 2003), organizational behavior (Zaheer and al., 1998) to become today an inescapable aspect of Interorganizational issues (Sako 1997).

Trust is, thus, a multidisciplinary concept considered as a key factor in the success of interactions, and as one of the mechanisms of governance of both organizations and networks to fill the gaps in the contract Piovesan, Pascal \& Claveranne (2007).

Deutsh (1958) pointed out the influence of the psychological dimension by defining trust as follows: "An individual may be said to have trust in the occurrence of an event if he expects its occurrence and his expectation leads to behavior which he perceives to have greater negative motivational consequences if the expectation is not confirmed than positive motivational consequences if it is confirmed " (p.266). According to this view, trust results, therefore, from the irrational choice a person makes, faced with the uncertainty of an event for which the estimated losses are much higher than the gains

Arrow (1972) notes that "Virtually all commercial transaction has in within itself an element of trust, certainly any transaction conducted over a period of time. It can be plausibly argued that much of the economic backwardness in the world can be explained by the lack of mutual confidence" (p.357)

Later, Arrow (1974) in his book "the limits of organization" places trust in the heart of invisible institutions, with ethical and moral principles. "Trust and similar values, loyalty and truth-telling, are examples of what the economist would call "externalities". They are goods, they are commodities. They have real, practical economic value, they increase the efficiency of the system, enable you to produce more goods more of whatever values you hold in high esteem. But they are not commodities for which trade on the open market is technically possible or even meaningful. ". (p. 23).

Shapiro (1987), reveals the need to introduce some degree of confidence in economic activity, especially institutional trust (at the level of society). For its part, Dasgupta (2000) suggests, in order understanding trust, to refer to "correct expectations about the actions of other people that have a bearing on one's own choice of an action when that action must be chosen before one can monitor the actions of those others "(p.51), and thus clearly articulates the role of uncertainty and risk associated with trust.

Barney and Hansen [23], on the other hand, define trust as "the mutual confidence that no party to an exchange will exploit another's vulnerabilities". (p. 176).

Ring and Van de Ven (1994) developed a framework describing the emergence, evolution and dissolution of inter-organizational relations. They argue that "understanding the willingness of the parties to rely on trust (confidence in the goodwill of others) to deal with uncertainty requires careful and systematic attention to the concrete processes by which personal relationships emerge between transacting parties; In this way, personal relationships can serve to shape and modify the evolving structure of a cooperative 
inter-organizational relationship. " (p. 93).

Building on arguments outlined by Ring and Van de Ven (1994) on the role of trust,

Ring (1996) suggests that two distinct forms of trust can be observed in economic exchange: fragile and resilient trust, describes the first form (fragile trust) as "a type that permits economic actors to deal with others, but in guarded ways", (p.152) because of the parties view of trust "is based on predictions that may or may not come to pass." (p.152), and notes that the second form (resilient trust) "rests not in the predictability of outcomes, but in a belief in the goodwill of others” (p155).

Hosmer (1995) attempting to draw the essentials from each of the approaches in which the concept of trust has been used in the literature of organizational theory and its related disciplines, propose a synthetic definition of trust : "Trust is the optimistic expectation by one person, group, or firm of the behavior of another person, group, or firm in a common endeavor or economic exchange, under conditions of vulnerability and dependence on the part of the trusting party, for the purpose of facilitating cooperation between both parties that will result in an ultimate joint gain but, given the lack of effective contractual, hierarchical, legal, or social enforcement methods, with reliance upon a voluntarily accepted duty by the trusted party to protect the rights and interests of all others engaged in the endeavor or exchange.” (p. 392-393).

Fukuyama (1995) proposed a more elaborate definition of trust as: "the expectations that arises within a community of regular, honest and cooperative behavior, based on commonly shared norms, on the part of other members of that community ".(p.26) and thus highlighted that the industrial competitiveness of states stems from trust, arguing that prosperous countries tend to be those where trade relations between people can be conducted informally and flexibly on the basis of trust thereby putting the culture and fabric of society at the heart of the understanding of success and economic failure.

Inspired by psychological and psych-sociological literature, Mc Allister (1995) defines interpersonal trust as "the extent to which a person is confident in, and willing to act on the basis of the words, actions and decisions of another" (p. 25) and distinguishes between two forms of interpersonal trust: "cognition-based trust, grounded in individual beliefs about peer reliability and dependability, and affect-based trust, grounded in reciprocated interpersonal care and concerns" (p. 25).

Lewicki and Bunker (1996), for their part, have established a sequential model of three levels of trust, according to which trust once established at one level, goes to the next level:

The first form is calculus-based trust grounded in the calculation of costs and benefits according to which the parties not only fear the punishment for violating trust, but also in the rewards to be derived from preserving it: "In a business relationship, the professional reputation of the other side can serve as a 'hostage'. If one party begins to violate the other's trust, the violated party can quickly let it be known, throughout the accused's network, that 
the other is a disreputable individual." (p. 120).

The second is the knowledge-based trust that develops over time in the permanent contact between the participants.

This form of trust is "grounded in other's predictability- knowing the other sufficiently well so that the other's behavior is anticipatable. Knowledge-based trust relies on information rather than deterrence ". (p. 121).

The third is Trust based on the identification that the parties know each other, and can anticipate the reactions of the other. This form of trust is based on "identification with the other's desires and intentions [...] trust exists because the parties effectively understand and appreciate the other's wants; this mutual understanding is developed to the point that each can effectively act for the other ". (p. 122).

According Sako (1997), the notion of trust implies that the partner has freedom of choice to take alternative courses of action. Thus, predictability in behaviour arises not because of constraints which force the other side to stick to a single Possible course of action, so he categorizes other reasons for predictability of behaviour and distinguishes between three type of trust: "contractual trust" (will the other party carry out its contractual agreement ?) "Competence trust" (is the other party capable of doing what it says it will do?) and "goodwill trust" (will the other party make an open-ended commitment to take initiatives for mutual benefit while refraining unfair advantage taking?). Later, He demonstrates the link between trust and performance through a study of automotive component suppliers in the United States, Europe and Japan.

Zaheer et al. (1998), for whom Inter-organizational trust refers to a collective sense of trust between the individuals in partner firms, defines interpersonal trust and inter-organizational trust as two distinct constructs, the first one is defined as; "interpersonal trust is the trust placed by the individual boundary spanner in her individual opposite member". (p. 142). The second as: "the extent of trust placed in the partner organization by the members of a focal organization”. (p. 142), and emphasizes the role played by trust in the performance of inter-organizational exchanges by reducing transaction costs.

In economic terms, trust can be defined as "the willingness to expose oneself to the possibility of opportunistic behavior by others" (Schmitz, 1999, p. 141)

Ireland and al. (2003) Note that, among other benefits, trust reduces the firm's internal and external transaction costs and can be used as an alternative governance mechanism. They also note that in the absence of trust relationships are often defined only by contracts, and this type of relationship can hinder knowledge transfer.

Veronique Le Gall (2012), for her part, defines trust as "the desire to make oneself vulnerable to the actions of another party under conditions of risk and uncertainty, by formulating positive expectations about the behavior of others" (pp. 18-19). 
Castaldo, (2003), using his excellent analysis of the many different elements offered in the various definitions, defines trust as "an overlaying and synthetic construct, such as attitude. It is naturally founded on beliefs relative to single characteristics of the counterpart and to situation-specific elements”. (p. 10)

Whether research is, therefore, of a behavioral nature emanating from sociologists who focus on shared norms within the group, or of economic nature emanating from economists who highlight risk taking and the distribution of gain, the preponderant role of trust is no longer neglected in interactions and exchanges between actors, and is a central element in business ecosystems.

\subsubsection{Role of Trust in Networks:}

Trust has been subject to many theoretical frameworks in goal to conceptualize it and its role within Competitiveness Pole

In this sense Boughanbouz and al. (2012) note that "the emergence of new organizational forms (networks, ...) and development strategies of alliance has led to new reflections on trust and its importance" (p. 9), thus, the importance of the role it plays in intra- and inter-organizational exchanges has led researchers to model it either according to the cluster, or according to the actors in the cluster, or again depending on the relationship between the actors. Indeed, according to Ahuja (2000), very dense networks facilitate trust and cooperation unlike less dense networks that are not suitable for the search for new ideas.

Ingram and Roberts (2000) analyse the benefits of network density and described how dense friendship networks affected the performance of Sydney hotels by increasing their profitability.

For his part Uzzi (1997) proposed that there are market based dyadic relationships (arm's length ties) governed by legally binding contracts or regulations, and trust based relationships (embedded ties) governed by social contracts and norms of reciprocity: "The optimal network structure to link to is a mix of arm's length and embedded ties, because each type of tie performs different functions: Embedded ties enrich the network, while arm's length ties prevent the complete insulation of the network from market demands and new possibilities" (p.59).

Gulati et al. (2000) argue that networks increase trust, reduce transaction costs, and significantly reduce information asymmetries: "one important implication of the embeddedness of firms in social networks is the enhanced trust between firms that can in turn mitigate the moral hazards anticipated at the out-set.[..]. Social networks promote trust and reduce transactions costs in several ways” (p. 209).

The reputation of the actors can play, also, a primordial role in the interactions and constitutes a condition allowing the establishment of a relationship of confidence (Pesqueux Y., 2009).

Similarly, the very nature of the inter-organizational relationship can generate trust: thus, 
from this perspective, the collaborative project is the most likely activity to build trust and launch the cooperation dynamic Fen Chong [42]. Because more we work together, more we trust each other and better we adapt to the circumstances.

\subsubsection{The Zucker's View of Trust}

In an interesting historical study of the US economy between 1840 and 1920 Zucker (1986) identified three basic modes of trust production in society

Zucker (1986), by defining trust as "a set of social expectations shared by all those involved in an economic exchange," considers that "trust is essential for stable social relationships" and "vital for maintenance of cooperation in society" or "necessary as ground for even the most routine everyday interactions ", and uses trust to explain the institutional sources of the economic structure.

Zucker (1986) notes, also, that both economics and organization theory recognize trust as "the most efficient mechanism for governing transactions. ","

By joining, then, in the continuity of the works of Arrow and Ouchi in organizational theory, Parsons and Garfinkel in sociology, according to which trust is defined as an efficient mechanism of transaction governance, Zucker (1986) proposes a global analysis based on the evolution of the degree of trust and distinguishes then three forms of trust according to their mode of production:

- Intuitu personae trust (Characteristic based trust) which is attached to a person according to the particular characteristics such as belonging to a particular family, ethnic group or group;

- Relational trust, (Process based trust) based on past or expected exchanges based on reputation or a donation / against donation;

- Institutional based trust, which is attached to a formal structure that guarantees the specific attributes of an individual or an organization. In this context, Zucker distinguishes between two types of institutional trust: that relating to a person or a company (e.g. a person's diploma, a company's mark) or that relating to an intermediary (e.g. insurance).

\section{Research Methodology}

The relationship between epistemology and methodology is not immediate, and the epistemological positioning of a search does not necessarily induce a specific method. However, the epistemological stance influences the path that will have to be taken by the researcher to produce knowledge.

First, we will define our positioning before articulating, then, with the adopted method.

\subsection{Choice of Interpretativism as Epistemological Positioning}

The choice of an epistemological positioning amounts to translating the nature of the targeted knowledge as well as to question the nature of the studied reality. 
However, to situate one's research in a paradigm has undeniable advantages, if only transparency towards readers. A clear advantage of the paradigm in which the study is presented is another advantage, all of which benefits the quality of the research.

Assume one paradigm or another allows, indeed, both to ensure a better consistency of the approach adopted and especially to set the scope.

In the context of our case, our research question aims above all to understand the functioning of the "Moroccan business ecosystem", which makes Tangier city emerge as pole of attractiveness to the automotive industry rather than the pure and simple explanation or the construction of the reality of this ecosystem.

Interpretativism has captured our attention. It appeared to us to take into account the contributions of each of the other positions (positivism and constructivism). Indeed, the business ecosystem that we study forms a network of actors, characterized by a relational dynamic that joins Zucker's view of trust, and by seeking the motivations of those actors who determined their adherence to This business ecosystem, as the interpretative approach does, we introduce the decisive role of perception of the phenomenon of these actors, in the reflection carried out in relation to the object of research.

This implies not to move away from these perceptions of the actors in the analysis of the discourses that we seek to analyze.

\subsubsection{Choice of the Case Study as Qualitative Method}

Yves Poisson (1983) stipulates that "the partisan researcher of the qualitative approach does not first try to quantify the phenomena observed in order to establish correlations. Instead, he tries to grasp reality as the subjects with whom he is in contact live it; he tries to understand reality by trying to penetrate inside the observed universe”. (p.371), while Yin (1994) argues that, if the research addresses either a descriptive or explanatory question or aims to understand the "how" or "why" of a phenomenon, the qualitative methodology based on case study proves to be the most relevant strategy.

The choice of the qualitative methodology was, then, a choice dictated by the objective of the research (to understand and explain), the type of research (exploratory) and by the object of the research (complex and little known phenomenon)

As far as the choice of the case method is concerned, it seems justified to us to use this method in view of our epistemological positioning (researchers adopting an interpretative positioning use it), of our research problem (which insists on the "how?") and existing theories on the subject (the existing theories or the grids of reading adopted have been little focused on our object of research).

\subsubsection{The Articulation of Our Abductive Approach}

According to Charreire and Durieux (1999) "to explore, the researcher adopts a process of inductive and / or abductive type, whereas to test, the latter uses a deductive approach"(p. 
60)

The notion of abduction has been introduced into epistemology by Charles S. Peirce [47], who describes it as "[...] process by which a confused concatenation of predicates is put in order under a predicate of synthesis".

Abduction is therefore close to deductive reasoning. But, unlike deduction, abduction is inherently uncertain. "The uncertainty may relate to the plausibility of the explanation, or concern the validity of the knowledge allowing the explanation" (Catellin (2004, p. 180);

The abduction can also be compared to the induction that concludes from the particular to the general, probably. But unlike induction, abduction often "infers something that we cannot observe directly". (Catellin (2004, p. 180). The exploratory nature of our research question involves an exploration process, and since our first field analysis is based on a reading grid drawn from the literature (Zucker view of trust). The studied variables are, then, both from the literature and in a second time emerging from the field during the interviews,

Therefore, our approach leads us to go back and forth between theoretical knowledge and empirical observations and therefore it is an abductive step.

\section{Results and Discussion}

\subsection{Data Collection}

With regard to the data collection technique, Thiétart \& al. (2007) states that: "The interview is a technique intended to collect, from the perspective of their analysis, discursive data reflecting in particular the conscious or unconscious mental universe of individuals". (p. 241).

In the same sense Grawitz (2001) asserts that it is "a process of scientific investigation using a process of verbal communication, to gather information, in relation to the fixed goal", it is therefore "a means privileged access to facts, representations and interpretations on the situations known by the actors" Wacheux (1996). Considering these criteria, the semi-structured focus interview therefore corresponds to the exploratory objectives of our research, so, an interview guide composed of open questions was developed.

This interview guide was constructed from the concepts found in the literature, taking into account the groups of words in the development of relevant themes ranging from the types of links between members to the types of collaborations and the objectives sought by companies ..., and the choice of variables allowing us to observe the trust in the speeches of the actors of the business ecosystem through indicators that can express, among other things, loyalty, respect for conventions or compliance with norms and rules imposed by the cluster itself.

On a sample of 15 companies operating in the automotive sector based in Tangier Free Zone (TFZ) who agreed to answer us and give us interviews, we conducted a total of 15 interviews, ranging in length from 30 minutes to 40 minutes, with an average duration of 35 minutes. 
For secondary data, we were able to acquire documents, management reports and institutional studies, which aim to complete the speeches of the partners resulting from the interviews carried out, and to put them in their general context.

\subsection{Speech Processing and Analysis}

The transcripts of the semi-structured interviews enabled us to collect a certain number of qualitative data "made of words or sets of words, written in narrative texts" (Miles and Huberman, 1994). That we used in our analysis to draw conclusions.

Thus, at first, we did a reading of the interviews in order to get a general idea about the functioning of the studied pole and the perceptions of the different actors concerning their implication in the project. The data were then analyzed. Thematic content according to the reading grid on trust and themes developed. Analysis that was done by hand and without the help of software, views that the study is in its exploratory phase and that the sample is restricted with a limited number of interviews,

Following the interviews, we note that all the interviewees have all confirmed first of all the importance of belonging to the cluster, which should give them an adequate situation perfectly suited to their needs. In this sense, they almost all insisted in one way or another on the significant influence of the institutional framework on the choice of membership in the pole of Tangier: "Our company settles where there is a an encouraging and promising business climate. ". Climate that some saw from the angle of political stability and legal security "The geographical position, the qualification of the workforce and especially the political stability and the legal security were our fundamental reasons to invest in Tangier" Thus, betting on the stability of the country and on the qualified human capital, and that others have seen from the angle of the effectiveness of the institutional structures determining the degree and the mode of coordination between actors of the pole to reduce the opportunism: "in addition to the geographical membership, the adhesion to the structures institutions determines the degree, but also the mode of coordination of the actors' actions". while others emphasize tax incentives and the culture of tolerance of the country as determinants of their choice "The choice of TFZ (Tangier Free Zone) membership was not a random choice but due to the fact that Morocco has several advantages over other countries, such as: the culture of openness and tolerance, the strong cost competitiveness, the incentive tax framework and the geographical position that facilitates exports to Europe. ", Culture that could guide managers to adapt their management according to the trust to focus : " If personal trust is critical to my business, given its context, I have interest in developing within my company social links ... "

Thus, according to the speeches of the actors of the ecosystem, we have spotted two types of trust:

- The intuitu personae trust (20\%): according to which the actors form a small community within which there are ties of social kinship between the members. 
- Institutional trust (80\%): according to which actors' behaviors are governed by a number of formal rules to reduce opportunism and give meaning to collective action. Relational trust is not sufficiently developed due to the lack of interaction between companies and the fact that the cluster is led by the state under the PPP partnership.

The results revealed that the business ecosystem is based essentially on the institutional trust in which the state regulates this ecosystem, and on the intuitu personae trust where the Moroccan cultural specificities linked among others to loyalty and collectivism constitute the cement of relations inter-organizational.

\subsection{Institutional Trust Guaranteed by the State}

The establishment of integrated industrial platforms (2IP), which are competitiveness clusters in Morocco, is associated with several measures introduced by public institutions: setting up infrastructure, tax incentives for local or foreign private investors, in addition to the commitment of the State to ensure the training of the necessary human resources, in particular the 70000 profiles having to fill the quality and the technicality required in the field.

The State seeks through these incentives (including the status of free zone, and installation aids up to $10 \%$ of the total amount of the investment); and programs (including the provisions of the Hassan II fund which concern, inter alia, commitments made by the State in favor of investment projects governed by the framework agreement: Kingdom of Morocco / Renault Group / Renault Tangier Mediterranean Company ) to send positive signals to the industrial and technological ecosystem in Morocco and abroad, to improve the level of investor confidence in the Moroccan economy, and to highlight and capitalize on the trades in which Morocco has comparative advantages, as is the case of the automobile industry, We are, then, in front of an institutional trust in the sense of Zucker (1986) as long as it is the Moroccan State which directs and frames the policy industrial and economic development of the country, especially if we consider that the State with this orientation and this framework is a structure guaranteeing actions to limit, the impact of uncertainty and the risks of opportunism, and therefore serve as an assurance and a source of "institutional trust".

\subsection{Intuitu Personae trust fostered by Cultural Specificities}

Numerous researchers in Management have been interested in the Moroccan cultural context considered as a strong context. (D'iribarne, Hofstede, Trompenaars...) And based on the models proposed, we find that the intuitu personae trust within the cluster is due to the fact that our national culture influences the nature of the trust developed with the partner, the nature of the developed engagement and relational integration. Indeed, as Hofstede [53] points out, the Moroccan national culture is characterized: First, by a high degree of collectivism where the relations are characterized by strong links and a predisposition to mutual aid, and where the individual benefits the group's benevolence and protection, in return for its loyalty, in line with the connivance defined by Marcon \& al. (2014) as a moral commitment of members to the organization. Secondly, by a weak control of the uncertainty 
according to which individuals believe in freedom and are much more tolerant of difference of opinion and respect only the most essential formal rules.

Similarly, the Moroccan national culture is very diffuse in nature. Insofar as the members consider the private life as related to the professional life, and attach more importance to the personal contact than to the professional relation. We are no longer bound by a contract, but with a personal and human contact, as Trompenaars and Hampden-Turner (2000) indicate: "when the whole person is involved in a business relationship, there is a real and personal contact, instead of the specific relationship prescribed by a 'contract". In many countries a diffuse relationship is not only preferred, but necessary before business can proceed."(p. 9)

For its part, Maache (2002) affirms for the dimension " hierarchical distance " that "it is clear that Moroccan culture has always admitted long hierarchical relations". (p.21)

In the same sense D'iribarne (1989) notes that in the context of countries with a strong hierarchical distance relations between subordinates and superiors are often charged with affectivity, and that in this type of culture, trust tends to develop on affective bases, the very essence of which is informal practices that reflect the desire to do more than is formally expected to do, and allow certain tasks which have not been formally provided for by the contractual terms to be performed. (Sako, 1992), and this, of course, links to the trust intuitu personae in Zucker's grid.

But beyond the revelations of the results, the discussion also allows us to highlight the existence of a dual public institutional logic: the creation of an automotive hub in Tangier aims at, both, the development of competitiveness companies through the various institutional incentives offered to them, and at the same time, support the competitiveness of the territory, in this case Tangier, and confirm it as an automotive hub by these various incentive procedures.

Indeed, the launch of the automotive industry in Tangier greatly increased Morocco's export capacity, and resulted, through the installation of some thirty international subcontractors at the Renault plant, a chain of supply of a range of equipment manufacturers supplying the Renault plant and many other factories in Spain. (Ford for example).

\section{Conclusion}

If the concept of ecosystem is not recent, and works on FDI and trust are abundants in various fields, the question of FDI in an ecosystem context, seems to us, however, little explored in the studies concerning Morocco, that is the reason why we found it interesting to test the grid of Zucker (1986) on trust in the Moroccan innovation ecosystem in order to analyze how the three components of this grid articulate between the actors of the ecosystem and especially FDI. For this we chose the case of the pole of the automotive industry of Tangier.

However, any research conceals, obviously, weaknesses either methodological or theoretical, however, despite the limitations of the work done, our research shows the role played by the institutional and intuitu personae trust on the one hand in the choice of Tangier by the FDI 
and secondly in the inter-organizational interactions, and consequently the confirmation of Tangier as pole of the automotive industry. Confirmation that was anchored even more, first, by the signing in 2016 of the construction agreement by the Chinese group Haite of the "Mohammed VI Tanger Tech City" which will host about 200 Chinese companies operating, among others, in the automotive industry and the aeronautics industry, and then by signing in September 2017 the installation agreement for the first time in its history in Africa the Italian supplier of shock absorbers of Fiat Chrysler group, Magneti Marelli in Tangier, and most recently, in December 2017, by signing agreements to launch 26 industrial projects in the automotive sector, including 13 in Tangier.

\section{References}

Ahuja, V. (2000). Building Trust in Electronic Commerce. Journal IT Professional, 2(3), 61-63. https://doi.org/10.1109/6294.846215

Al Maache, M. (2002). Peut-on parler d'un mode de gestion marocain à l'instar des modes de gestion américain et japonais ? Cahiers de recherché $n^{\circ}$ 9. ISCAE Casablanca.

Arrow, K. J. (1972). Gifts and Exchanges. Philosophy \& Public Affairs, 1(4), 343-362.

Arrow, K. J. (1974). The Limits of Organization. W.W.Norton \& Company. New York,

Astley, W. G., \& Fombrun, C. J. (1983) Collective Strategy: Social Ecology of Organizational Environments. The Academy of Management Review, 8(4), 576-587.; https://doi.org/10.5465/AMR.1983.4284657

Barney, J. B., \& Hansen, M. H. (1994). Trustworthiness as a Source of Competitive Advantage. Strategic Management Journal, 15. Special Issue: Competitive Organizational Behavior, pp. 175-190. https://doi.org/10.1016/B978-0-12-498640-4.50011-1

Boughanbouz, C. al. (2012) Inter-organizational trust in the competitiveness pole. The 11th world congress of the IFSAM, University of Limerick, Ireland, <halshs-00833518>

Buckley, P. J., \& Casson, M. C. (2001) The Future of the Multinational Enterprise, London: Macmillan [Basingstoke, Hants: Palgrave Macmillan, 25th Anniversary ed. 2001. https://doi.org/10.1057/ palgrave.jibs.8400024

Castaldo, S. (2003). Trust Variety-Conceptual Nature, Dimensions and Typologies. In IMP Conference Lugano, Switzerland, 4-6 September Available at: http://impgroup.org/uploads/papers/4317.pdf [Accessed 30.01. 2017].

Catellin, S. (2004). L'abduction: une pratique de la découverte scientifique et littéraire. Revue HERMES $\mathrm{n}^{\circ} 39$ - Critique de la Raison Numérique. pp. 179-185, https://doi.org/10.4267/2042/9480

Charreire, S., \& Durieux, F. (1999). Explorer et tester. In Thiétart et coll., Méthodes de recherches en management, Paris, Dunod, pp 57-80. 
D’Iribarne, P. (1989). La logique de l'honneur : Gestion des entreprises et traditions nationales. éditions du Seuil, Paris,

Dasgupta, P. (2000) Trust as a Commodity. In Gambetta, Diego (ed.), Trust: Making and Breaking Cooperative Relations, chapter, 4, 49-72.

Deutsh, M. (1958). Trust and Suspicion. The Journal of Conflict Resolution, 2(4), 265-279.

Fen Chong, S. (2009). Le pilotage chemin faisant émergence des modes de gouvernance et de pilotage des pôles de compétitivité, thèse de doctorat en sciences de gestion. Université PARIS-DAUPHINE,

Fukuyama, F. (1995). Trust: The Social Virtues and the Creation of Prosperity. Free Press, p.26,

Globerman, S., \& Shapiro, D. M. (1999). The Impact of Government Policies on Foreign Direct Investment: The Canadian Experience. Journal of International Business Studies, 30(3), 513-532, https://doi.org/10.1057/palgrave.jibs.8490081

Grawitz, M. (2001). Méthodes des sciences sociales. 11ème éd. Paris, Dalloz,

Gueguen, G., \& Torres, O. (2004). La dynamique concurrentielle des écosystèmes d'affaires. Revue française de gestion, 1(158), 227-248. https://doi.org/10.3166/rfg.148.227-248

Gulati, R., al. (2000). Strategic Networks. Strategic Management Journal, 21(3), 203-215. https://doi.org/10.1002/(SICI)1097-0266(200003)21:3<203::AID-SMJ102>3.0.CO;2-K

Hirsh, S. (1976). An International Trade and Investment Theory of the Firm. Oxford $\begin{array}{llll}\text { Economic } \quad \text { Papers, New 28 } & \text { Series, } 270 .\end{array}$ https://doi.org/10.1093/oxfordjournals.oep.a041344

Hosmer, L. T. (1995) Trust: The connecting link between organizational theory and philosophical ethics. Academy of Management. The Academy of Management Review, 20(2), 379-403. https://doi.org/10.2307/258851

Hymer, S. (1960). The International Operations of National Firms: A Study of Foreign Direct Investment. Ph.D. Dissertation, Massachusetts Institute of Technology.

Iansiti, M., \& Levien, R. (2004). The Keystone Advantage: What the New Dynamics of Business Ecosystems Mean for Strategy, Innovation, and Sustainability. Harvard Business School Press.

Ingram, P., \& Roberts, P. W. (2000). Friendships among Competitors in the Sydney Hotel Industry. American Journal of Sociology, 106(2), 387-423, https://doi.org/10.1086/316965

Ireland, R. D., Hitt, M. A., \& Sirmon, D. G. (2003). A Model of Strategic Entrepreneurship: The Construct and its Dimensions. Journal of Management, 29(6), 963-989. https://doi.org/10.1016/S0149-2063_03_00086-2 
Le Gall, V. (2012). La construction de la confiance : le cas des alliances stratégiques en biotechnologie. Thèse de doctorat en Administration option stratégie et gestion des opérations. HEC Montréal Affiliée à l’Université de Montréal,

Lengnick-Hall, C. A., \& WOLFF, J. A. (1999). Similarities and Contradictions in the Core Logic of Three Strategy Research Streams Networks. Strategic Management Journal, 20(12), 1109-1132. https://doi.org/10.5465/AMR.1989.4308370

Lewicki, R. J., \& Bunker, B. B. (1996) Developing and Maintaining Trust in Work Relationships. » In Trust in Organizations, Frontiers of Theory and Research, edited by R. M. Kramer, and T. R. Tyler, 114-139. Thousand Oaks, ca: Sage.. https://doi.org/10.4135/9781452243610.n7

Macron, G., \& Dorigo, L. (2014). A caring interpretation of stakeholder management for the social entreprise Evidence from a regional survey of micro social cooperatives in the Italian welfare mix. Working Papers series $n^{\circ} .1$. Department of Management at Università Ca' Foscari Venezia.

McAllister, D. J. (1995). Affect and Cognition-Based Trust As Foundations For Interpersonal Cooperation in Organizations. Academy of Management Journal, 38(1), 24-59. https://doi.org/10.2307/256727

Miles, M. B., \& Huberman, A. M. (1994). Qualitative Data Analysis. Second Edition SAGE Publications.

Moore, J. F. (1993). Predators and Pray: a new ecology of competition. in Harvard Business Review may-June, pp 75-86.

Mucchielli, J. L. (1991). Alliances stratégiques et firmes multinationales: une nouvelle théorie pour de nouvelles formes de multinationalisation. Revue d'économie industrielle, vol. 55. L'économie Industrielle internationale: Une discipline en construction. pp. 118-134; https://doi.org/10.3406/rei.1991.1354

Mucchielli. J. L. (1985). Les firmes multinationales : mutations et nouvelles perspectives. Edition Economica Paris

Pecqueur, B. (2007). L’économie territoriale : une autre analyse de la globalization. L'Économie politique, 1(33). https://doi.org/10.3917/leco.033.0041

Pesqueux, Y. (2009). Un modèle organisationnel en confiance-coopération. Management Prospective Ed., Management \& Avenir, 1(21), 261- 272.

Piovesan, D., Pascal, C., \& Claveranne, J. P. (2007). Les visages de la confiance. Restructurations et gouvernance des cliniques privées. Communication pour les 29èmes Journées des Économistes de la Santé Français. Université Catholique de Lille.

Poisson, Y. (1983). L'approche qualitative et l'approche quantitative dans les recherches en éducation. Revue des sciences de l'éducation, 9(3), 369-378. 
https://doi.org/10.7202/900420ar

Ring, P S., \& Van De Ven, A H. (1994). Developmental processes of cooperative Interorganizational relationships. Academy of Management Review, 19(1), 90-118. https://doi.org/10.2307/258836

Ring, P. S. (1996). Fragile and Resilient Trust and their roles in Economics exchange. Business \& Society, 35(2), 148-175. https://doi.org/10.1177/000765039603500202

Sako, M. (1992). Prices, quality and trust: inter-firm relations in Britain and Japan. Cambridge University Press. https://doi.org/10.1017/CBO9780511520723

Sako, M. (1997). Does Trust Improve Business Performance? Ctuistel Lane and Reinhard Backmann (eds.) Trust Within and Between Orgmizations Oxford University Press.

Schmitz, H. (1999). From ascribed to earned trust in exporting clusters. Journal of International Economics, 48(1), 139-150, https://doi.org/10.1016/S0022-1996(98)00074-9

Sekkat, K., \& Veganzones-Varoudakis, M. A. (2004). Trade and Foreign Exchange Liberalization, Investment Climate, and FDI in the MENA Countries. Working paper DULBEA.N5.

Shapiro, S. P. (1987). The Social Control of Impersonal Trust. American Journal of Sociology, 93(3), 623-658,

Thietart, R. A., al. (2007). Méthodes de recherche en management, 3ème édition, Dunod, Paris.

Torres-Blay, O. (2000). Economie d'entreprise : organisation, et stratégie à l'aube de la nouvelle économie. Economica

Trompenaars, A., \& Hampfden-Turner. (2000). Riding the waves of culture: understanding diversity in global business. Nicholas Brealey Publishing, London.

Uzzi, B. (1997). Social structure and competition in interfirm networks: the paradox of embeddedness. Administrative science quarterly, 42(1), 35-67. https://doi.org/10.2307/2393808

Vernon, R. (1966). International Investment and International Trade in the Product Cycle. The Quarterly Journal of Economics, 80(2), 190- 207. https://doi.org/10.2307/1880689

Wacheux, F. (1996). Méthodes qualitatives et recherche en gestion. Ed. Economica.

Wilhelms, S. K. S. (1998). Institutional FDI Fitness: Determinants of Foreign Direct Investment to Emerging Economies. PhD Thesis. Medford, MA: Fletcher School of Law and Diplomacy.

Yin, R. K. (1994). Case Study Research: Design and Methods (2nd Ed.). Applied Social Research Methods Series Volume 5; SAGE Publications, 


\section{Macrothink}

Business Management and Strategy

ISSN 2157-6068 2018, Vol. 9, No. 1

Zaheer, A. al. (1998). Does Trust Matter? Exploring the Effects of Interorganizational and Interpersonal Trust on Performance. Organization Science, 9(2), 141-159. https://doi.org/10.1287/orsc.9.2.141

Zucker, L. G. (1986). Production of Trust: Institutional Sources of Economic Structure, 1840-1920. Research in Organizational Behaviour, 8, 53- 111.

\section{Copyright}

Copyright for this article is retained by the author(s), with first publication rights granted to the journal.

This is an open-access article distributed under the terms and conditions of the Creative Commons Attribution license (http://creativecommons.org/licenses/by/4.0/). 